\title{
EGFR NM_005228.3:C.1793G>T
}

National Cancer Institute

\section{Source}

National Cancer Institute. EGFR NM 005228.3:C.1793G>T. NCI Thesaurus. Code C159432.

A nucleotide substitution at position 1793 of the coding sequence of the EGFR gene where guanine has been mutated to thymine. 